\title{
STORYTELLING AND PRODUCT STOCKING: STRATEGIES APPLIED BY DIASPORA TOURISTS TO SYMBOLICALLY EXTEND THE VISIT TO THEIR COUNTRY OF ORIGIN
}

\author{
Denis Berberović \\ Emir Kurtović
}

https://doi.org//10.20867/tosee.06.6

\begin{abstract}
Purpose - Purpose of this study is to understand how diaspora tourists as a specific tourist segment symbolically extend their holiday in the country of origin upon returning to the country of current living.

Methodology - Aim of the research was to disclose underlying meanings of this specific consumption pattern. Data was collected through 24 semi-structured in-depth interviews with diaspora members from Bosnia and Herzegovina. Analysis was inductive, starting with microanalysis, proceeding then with axial coding around the revealed concept. Throughout analysis the comparative method was applied, alongside researcher's diary and memos as analytic tools. Findings - The concept of 'bridging' explains how diaspora tourists cross over from one reality to another on a symbolical level, i.e. when travelling back from the country of origin. It also is a symbolical bridging between complex of identities: the past identities and the present identity, which they have constructed in countries of current living. They seem to use two major strategies: storytelling and product stocking.

Contribution - This paper reveals a new concept among diaspora tourists, i.e. their approach to extend their visit to the country of their origin on a symbolical level by using symbolically laden products. The research is further contributing by disclosing that diaspora tourists apply two different strategies in order to symbolically extend their home country holiday: the story telling strategy and the stocking strategy. Finally, it also suggests that the stocking strategy has two phases; the first phase being 'symbolic representation filling phase' and the second phase labelled as 'mainstream trend purchase phase'.
\end{abstract}

Keywords: storytelling, product stocking, symbolic consumption, diaspora tourist, home country.

\section{INTRODUCTION}

United Nations World Travel Organization (UNWTO) reports diaspora tourism to be one of the most important and sustainable market opportunities in contemporary tourism (UNWTO 2017). The United Kingdom's Ministry of Foreign Affairs (UKMFA) acknowledges the importance of diaspora tourists particularly for developing countries (UKMFA 2020). Yet the academic community has so far granted only limited attention to this rising tourist segment. Griffin and Dimanche (2017) argue for a rise of investigation into this tourist segment because the world is changing in the direction of increasing growth of diaspora communities and its rising relevance for the tourism industry. In addition to this, the evolution of family accelerates, causing many family members to live apart in different cities, countries, and continents. Hence the greater 
ToSEE - Tourism in Southern and Eastern Europe, Vol. 6, pp. 81-94, 2021.

D. Berberović, E. Kurtović: STORYTELLING AND PRODUCT STOCKING ...

need to understand travel aspects related to this segment of consumers (Weaver et al. 2017; Li and McKercher 2016).

A number of scholars regard diaspora traveling to the country of their origin through the lenses of hybrid (consumer) identity construction. They claim such travels are not merely trips, but have a strong interpretative side to it, carrying strong symbolism and having attached a variety of underlying meanings (Bryce et al. 2017; Thompson and Tambyah 1999; Belk 1988). Therefore this research sought to investigate how do diaspora tourists extend on a symbolical level the visit to their country of origin?

\section{THEORETICAL FRAMEVORK}

\subsection{Consumer identities}

This paper therefore seeks to understand diaspora members as tourists applying the perspective of consumer identities, symbolic consumption and consumer realities, theoretical concepts nested in CCT - Consumer Culture Theory (Arnould and Thompson 2005).

It has been acknowledged by many scholars within the CCT community that consumer identity projects are symbolically constructed as a continuous two-way process of influence between the reality and the consumer (Ourahmoune 2016; Arnould and Thompson 2005; Venkatesh et al. 1993; Belk 1988; Holbrook and Grayson 1986). Living in a post-postmodern world of having plethora of identities constructed by products, and among other things, places visited, consumers engage in a playful interaction with one or more realities they have on disposal (Firat et al. 1994).

In fact, the question of reality is also a complex one. From the CCT perspective, consumers are believed not to engage only in construction of different identities; they are also perceived to participate in the construction of different realities - again through purchase and consumption of different products and brands (Arnould and Thompson 2005). As identities and realities are constructed on a symbolic level, consumption as the main construction activity needs to be performed on symbolic level as well. Hence symbolic consumption, as the main technique for constructing identities and realities (Belk 1988), is focused rather on employing symbols than utilitarian aspects of products. Symbols imply specific meanings attached to products and brands (Witt 2010).

One of these consumer-reality interactions are diaspora tourists' travels from country of current living to countries of origin. Regarded as transitions between different realities, these travels add to hybrid identity projects of diaspora members (Tie et al. 2015; Thompson and Tambyah 1999). Of particular significance are places visited, as well as products and brands purchased during the visit to country of origin. They all carry very specific meanings for diaspora tourists, arousing emotions and bringing up memories. 
ToSEE - Tourism in Southern and Eastern Europe, Vol. 6, pp. 81-94, 2021.

D. Berberović, E. Kurtović: STORYTELLING AND PRODUCT STOCKING ...

\subsection{Diaspora tourists}

Tourism affects cultural identity and place attachment among diaspora members (Li and McKercher 2016). When diaspora members travel to their countries of origin for holidays, the travel is more than just a holiday trip. Tie et al. (2015) believe it to be an important hallmark of the identity-construction process as it represents a strong shaping force of new and hybrid identities. Bryce et al. (2017) consider diaspora tourists to be consuming the past while visiting countries of their origin. "Integral to a sense of who we are, is a sense of our past." argues Belk $(1988,148)$, leading to suggest the intertwining of identity construction processes which relate simultaneously to the past and the present.

While Weaver et al. (2017) acknowledge that the definition of 'home' is quite ambiguous for diaspora members, research conducted by Huang et al. (2018) suggests that firstgeneration diaspora members do have a high level of homeland attachment, leading to the conclusion that the definition of home in their case is apparent. The sentiment of homeland attachment is also amplified by the need to strengthen social ties and fight the acculturation processes they perceive to be exposed to in the countries they live. In regards to social ties, particularly outstanding is the need to strengthen more kinship than friendship (Hung et al. 2013).

But even after they return from their visits to countries of origin, research suggests that diaspora tourists are still in a transitional phase when being back to the country of living. Effects and influences remain for a certain period (Yin et al. 2017). Or to put it in more profound words of Ceisel $(2015,450-451)$ who claims that by using travel to bring the past to the contemporary, diaspora tourists actually create a presentation of themselves: "The experience of "heritage" through tourism works to present us to ourselves, construct our pasts to be interpolated into our present, and in doing so, fixes/freezes the flows of history and culture. Rather than a voyage of discovery, it is a voyage of recovery."

\subsection{Storytelling}

Humans are homo narrans, individuals who construct and create stories. Such narratives are seen to be communicative vessels which transfer values and meanings (Chronis 2012). According to Woodside et al. (2007) individuals think more narratively than argumentatively and these memories of past experiences are organized in episodes rather than in the order they really appeared, providing thereby clues of both conscious and unconscious thinking (Zaltman 2003). It is a highly persuasive communication vessel because it is the storyteller's emic point of view. „Emic and etic interpretations of travel experiences create a bricolage of the travellers' experiences“, argue Martin and Woodside $(2011,27)$. Storytelling offers a simple but effective strategy to consumers to tell complex consumer experiences with all related emotions and perceptions in a very short period (Wilson and Desha 2016). 
ToSEE - Tourism in Southern and Eastern Europe, Vol. 6, pp. 81-94, 2021.

D. Berberović, E. Kurtović: STORYTELLING AND PRODUCT STOCKING ...

\subsection{Souvenirs}

One of the hallmarks of any travel is a souvenir ${ }^{1}-$ be it a purchased or an else how gained object - which plays a significant role in the diasporic travel undertaking. These indispensable items in diaspora travels are tangible means representing intangible elements such as values, emotions, and memories, all blended into unique travel experiences (Lin and Mao 2015; Paraskevaidis and Andriotis 2015). Souvenirs are of particular importance because they often symbolise cultural values and places visited (Soukhathammavong and Park 2019). Food has particularly turned out to be important as a souvenir because it represents a tourism destination with all its facets (Lin and Mao 2015).

Yet souvenirs have not been sufficiently researched, particularly the role of these items in the post-travel period, once the traveller has returned to the country of living (Paraskevaidis and Andriotis 2015). Looking from the CCT perspective of using products for the purpose of identity construction, souvenirs seem to be particularly influential. In addition to this, previously it has already been argued that diaspora tourists are an increasingly relevant but under-researched area in tourism research (Griffin and Dimanche 2017; Weaver et al. 2017; Li and McKercher 2016).

\section{METHODOLOGY}

This research was part of a larger research project which had the purpose to understand the identity construction process of diaspora tourists while visiting the country of origin. One of the aims of that project was to understand the role of products and other items diaspora tourists bring back from their travels to the country of their origin. This paper leans on that aim, as the previous theoretical discussion has pointed. Research questions was, how do diaspora tourists extend on a symbolical level the visit to their country of origin?

A qualitative research design was applied. Dutt and Ninov (2017) suggest that qualitative research is particularly suitable in cases when emigrants take the role of tourists in the country of their origin, because it fosters a deeper understanding of their travel experience and helps uncover meanings they attach to it.

A total of 24 in-depth semi-structured interviews were conducted with diaspora tourists during their visit to Bosnia and Herzegovina, their country of origin. Interviews were conducted from spring to autumn 2018. Bosnia and Herzegovina has been selected as it has one of the largest diaspora communities in the world relative to its population. With approximately 3.8 million inhabitants in the country, Bosnia and Herzegovina is estimated to have 2 million individuals originating from Bosnia and Herzegovina but living across the world. Diaspora members count to the most important contributors to the economy of Bosnia and Herzegovina - as tourists, investors, and financiers (MHRRBH 2016).

\footnotetext{
${ }^{1}$ souvenir; fr. - to remember, memory; eng.
} 
ToSEE - Tourism in Southern and Eastern Europe, Vol. 6, pp. 81-94, 2021.

D. Berberović, E. Kurtović: STORYTELLING AND PRODUCT STOCKING

In-depth interviews were applied by one of the authors with expertise in qualitative research. Interviews were conducted during the diaspora members' visit to Bosnia and Herzegovina in order to be sure that the interviewee is fully immersed in the tourist experience. The interview setting was relaxed and supportive. All these methodological decisions lead to ensure that the interviewee was put in the position to be able to extensively explore and elaborate her/his emic perspective. Interviews were recorded and transcribed. Notes during interviews were taken by the interviewer. Later interviews were transcribed and memos were created. Analysis relied on open coding, axial coding and finally selective coding (Flick 2009). Collected data was processed anonymously and names of interviewees were changed for the purpose of anonymous presentation of data.

\section{RESEARCH RESULTS AND DISCUSSION}

\subsection{Sample characteristics}

In order to gain wider understanding and theoretical generalization (Corbin and Strauss 2015), the sample was heterogeneous in terms of demographics and geographic criteria. Sample consisted of Bosnian-Herzegovinian diaspora members different ages, ranging from 30 to 50 years old, education levels from high school education to master degree, and the country of current living (USA, UAE, Australia, Germany, Netherlands, Croatia).

\subsection{Results}

Interviews revealed that upon return to the country of current living, diaspora tourists seek to bridge the transfer from one reality (country of origin) to another (country of current living). Hence the concept of 'bridging' was established and elaborated further through interviews.

The concept of 'bridging' explains how diaspora members cross over from one reality to another on a symbolical level, i.e. when travelling back home from Bosnia and Herzegovina. It also is a symbolical bridging between complex of identities: the past idealised identities which are related to the past spent in Bosnia and Herzegovina and the present identity, which they have constructed in countries of current living. They seem to use two major strategies: storytelling and product/brands stocking.

Telling stories about the visit to the country they originate from is one of the ways how diaspora members bring the sense of home from country of origin to country of current living. Such narratives serve as bridges from one reality (context they originate from) to another (context they currently live in). These narratives 'bumper' the transition from one reality to another. 
ToSEE - Tourism in Southern and Eastern Europe, Vol. 6, pp. 81-94, 2021.

D. Berberović, E. Kurtović: STORYTELLING AND PRODUCT STOCKING ...

„Interviewer: Upon return to USA, how do you feel few days or weeks?

Well, you know how it is. When I return there, first few weeks, perhaps four or more, while I see my local friends there, the socializing is mainly going to be about how it was in Bosnia, in Sarajevo, did we go to seaside, so that's the story going to be. At least the first meeting with everyone. That is what it is going to be based on or around it, the focus will be on our trip. But life there is simply like that, you have to go back and get on, the job, bills, and you move on. If there wasn't the returning back to reality, it'll be interesting. I think there would be a serious dose of depression. You know, when you are constantly surrounded by people and then you return there, you are not alone but the context is completely different, different world, different people, so... " (Emir, 34y-B1) Code: Storytelling about the visit to Bosnia and Herzegovina

Another bridging strategy is the usage of Bosnian-Herzegovinian products and brands in the country of current living. Respondents take different products with them from Bosnia and Herzegovina to their respective countries of current living and create stockings. Most of the products are purchased with the intention to be consumed after they have left Bosnia and Herzegovina.

"Interviewer: What do you take back with you to the country of current living?

I always take back with me Cedevita, Plazma, for kids because they like it...although those are not specifically Bosnian products, for us they are important because we connect it with Bosnia...basically we buy and bring many products in order when we get back, to have few more days to enjoy the stay in Bosnia by using those products. And that's it. " (Aleksandar, $47 y$ -B2) Code: Extending the visit through products

It follows that such delayed consumption of stocked products represents a symbolic stay extension and helps diaspora members to construct a visit to Bosnia and Herzegovina on a symbolic level every time the product is consumed. It means also that consumption patterns which entail local brands extend even years after leaving Bosnia and Herzegovina as following testimonial suggests. This applies even to brands which are not originally from the country of diasporas' origin, but are on a symbolical level related to the period of life spent in Bosnia and Herzegovina. This represents a stay extension and creates symbolic visit to Bosnia and Herzegovina every time the product is consumed, as following quotes reveal.

„Interviewer: Why do you take Cedevita with you? There are so many other juices.

I really love Cedevita but there is anywhere anything similar. At least I haven't found it so far.

So that is the reason I take it with me because I really love it. But other things... well, say

Bajadera. Also, was my favourite chocolate for ever. So that is the reason. But it is not that often that I say I have to take Bajadera with me because there are thousand types of chocolates and all hose sweet things, therefore it's OK. But Cedevita does not exist. So I have to buy it here." (Damir, 30y-B4) Code: Regional brands also support the visit extension

One respondent even reported to have regular shipments of products and brands that she got used to during her life in Bosnia and Herzegovina.

"Interviewer: What do your parents send you from Bosnia and Herzegovina?

My mum and dad regularly send products to me which I have used there all the time because I simply cannot find anything like that here. There are some products which are similar, but it's not the real thing. After all I have got used to our products and wouldn't change it. And 
ToSEE - Tourism in Southern and Eastern Europe, Vol. 6, pp. 81-94, 2021.

D. Berberović, E. Kurtović: STORYTELLING AND PRODUCT STOCKING ...

when I go out of these products, if we are not about to go to Bosnia, I order then a package from my parents." (Violeta, 30y-B5) Code: Familiar products which symbolise home

In addition to the aforementioned interpretation, some products are not available in countries of current living. Or, some product concepts (such as the above mentioned Cedevita) are different in Bosnia and Herzegovina than in country of current living. Hence, these are all reasons for stocking specific products and brands when in country of current living.

The stocking of products has experienced two phases: long-term and short-term stocking. First phase, the long-term stocking phase, was when typical Bosnian-Herzegovinian products where bought and places of current living (homes) were decorated with symbolic representations of Bosnia Herzegovina, such as photos, maps of Bosnia and Herzegovina, flags, even sport dresses.

\begin{abstract}
„Interviewer: And do you buy anything for yourself that reminds you of Sarajevo?
Well, I did before. But that is decreasing now... Like, some photographs of Sarajevo, city hall and so on, sometimes I buy the $20 \mathrm{~cm}$ format, perhaps slightly bigger. They call it ten-by-twelve inch, so it is like 20 to 30, or a bit bigger. That is what I used to buy. There is a huge map of Bosnia and Herzegovina, the one we used in Geography lessons in school (laughter). Some of these items are in my room, some are in the kitchen, and some in the living room. " (Emir, 34y - B6) Code: Decorating the current home with symbols of Bosnia and Herzegovina
\end{abstract}

As these products are usually long-lasting products, they have been stocked for a long period, hence their purchase has ceased. This phase can be labelled as 'symbolic representation filling phase'. Such products are also seen as personal investment purchase, due to their durability. Here functionality of the product seems to play also an important role.

„Interviewer: And what did you buy for yourself?

I bought two things. I bought one old silver ring, old-fashioned ring and one, it's like a basket, stitched. Handmade. And might take one carpet back with me. The price...ring was $25 \mathrm{KM}$ and the basket was around 40 I think. That's for a basket...probably a little too much. For the ring I felt that it was a good bargain. Both things are...old fashioned. Yeah. And both things are aesthetically pleasing. Pretty." (Hidajeta, 32y - B9)_Code: Functionality of symbolical decorations

Purchase of local products proceeded into second stocking phase, the short-term stocking phase. This phase implies purchase patterns which are more close to mainstream purchase patterns, such as healthy food purchase and consumption, popularity of both home-made and hand-made products, traditional products, price-value ratio, etc. This phase can be labelled as 'mainstream trend purchase phase' and it implies buying of products for immediate use, products which will last no longer until next visit (but probably even shorter).

„Interviewer: And is there anything you take back for yourself?

Ivana: Yes. Again, our products. We'll take this time, I went and bought full bag of things, common mallow tea, thyme tea. We buy it for ourselves but also for Maja. Perhaps even more for Maja. We'll buy honey, and stuff like that. Mostly that, that natural version. Healthy 
ToSEE - Tourism in Southern and Eastern Europe, Vol. 6, pp. 81-94, 2021.

D. Berberović, E. Kurtović: STORYTELLING AND PRODUCT STOCKING

version. The things that they don't have over there, what you cannot buy. That's what we take for ourselves.

Amar: they have it all but at the end of the day it's simply not the real thing.

Ivana: No! but there isn 't. you can't find homemade honey over there. " (Ivana, 33y and Amar,

$38 y-B 10)$ Code: Stocking of products for immediate use

The two bridging strategies, storytelling and product/brand stocking can also occur combined. Namely, stocked products/brands from Bosnia and Herzegovina are not always consumed only by diaspora members who brought them to their respective countries of living. They are, upon return, often shared with family and friends, as the following quote illustrates.

\begin{abstract}
„, When I am here, I buy Travnik cheese, cured meat, butter, sometimes I buy kadaif, that's it in regard to food. That is what I love, and if we are to talk about Travnik cheese, it is one of the cheeses with highest quality in the world. And that is who I am, that is my youth. I purchase greater quantities and take it with me and when I come home, I call my friends and tell them, come now, I bring specialities from Sarajevo to share and eat together. And then I make something like Bosnian dinner. " (Nađa, 50y-B14) Code: Storytelling supported by BosnianHerzegovinian products
\end{abstract}

Another important finding related to buying of products of Bosnian-Herzegovinian origin is the context of purchase. Same products and brands of Bosnian-Herzegovinian origin which are available both in Bosnia and Herzegovina and in the country of current living have not equal purchase satisfaction. Purchase satisfaction of such products and brands seem to be higher when bought in Bosnia and Herzegovina.

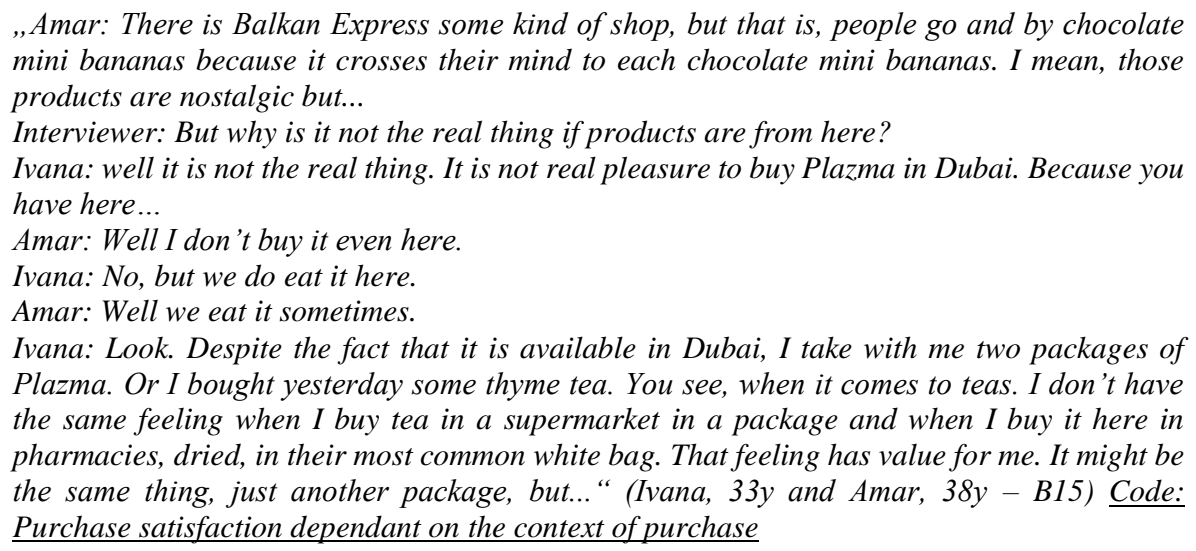

The main argument of this concept is that diaspora members have different ways of bumping the reality switch, i.e. smoothening the change of contexts when returning back from one reality to another (from Bosnia and Herzegovina to country of current living). This applies also to their switch between identities. In other words, they try to bridge the travel from one reality to another, which on a symbolical level is a travel from one identity (or more of them) to another. Two major bridging strategies emerged: storytelling and $\mathrm{BH}$ brands/products stockings. Storytelling is straight forward, implying 
ToSEE - Tourism in Southern and Eastern Europe, Vol. 6, pp. 81-94, 2021.

D. Berberović, E. Kurtović: STORYTELLING AND PRODUCT STOCKING ...

sharing experiences of the time spent in Bosnia and Herzegovina with friends and family in the country of current living.

Stocking is a rather complex bridging strategy. It implies purchasing products for personal usage. The purchase of such products seems to go through two phases - with the first phase being 'symbolic representation filling phase' and the second phase labelled as 'mainstream trend purchase phase'. In the early stage of purchasing stocking products such purchase was present during first visits to Bosnia and Herzegovina upon changing the country of living. Most of the purchase of local products was focused on their clearly visible symbolic representation of Bosnia and Herzegovina i.e. buying products and brands which symbolically represent the home country (e.g. flags, maps, national team dresses, photos, paintings, etc.).

Diaspora members 'filled' their homes with such products in order to expose a strong symbolical representation of their country of origin in current homes abroad. These products usually have long durability therefore are still present in the homes of diaspora members in their respective countries of living (also called long-term stocking phase). Such purchase ceased with time and diaspora members moved to buying products which match mainstream purchase trends such as healthy living, eco-friendly products, homemade products, etc. Such products are bought for immediate use. This phase is also labelled as short-term stocking phase because such products last rarely until the next visit is due. Most of the purchase of diaspora members is currently in this mainstream trend purchase phase. However, it must be noted that even products purchased in the second phase are more attractive to diaspora consumers if they are a symbolic representation of Bosnia and Herzegovina. Or, if they symbolically represent the period of life spent in Bosnia and Herzegovina. Often these two meanings coincide. Furthermore, although products from the latter phase can often be found in countries of current living in specialized shops offering products and brands from Balkans, such products and brands are more attractive to diaspora buyers when they are bought during their visits in Bosnia and Herzegovina.

The conclusion follows that purchase context plays a significant role when making a purchase decision; and, purchase context plays a significant role in consumption satisfaction, as research participants testified that they are more satisfied with consuming products bought in Bosnia and Herzegovina than consuming same products when bought in countries of current living. A possibility of mixing these two strategies also exist and is employed by diaspora members. Namely, they invite friends to come over upon their return to share their experience and together consume products which they have bought.

Concept of bridging consists of a family of codes which are given in Table 1. As codes are derived from quotes, the table contains also quotation codes. 
ToSEE - Tourism in Southern and Eastern Europe, Vol. 6, pp. 81-94, 2021.

D. Berberović, E. Kurtović: STORYTELLING AND PRODUCT STOCKING ...

Table 1: Concept of 'bridging' - overview of codes and quotes

\begin{tabular}{lc}
\hline Code & Quotation \\
\hline Storytelling about the visit to Bosnia and Herzegovina & B1 \\
Extending the visit through products & B2, B3 \\
Regional brands also support the visit extension & B4 \\
Familiar products which symbolise home & B5 \\
Decorating the current home with symbols of Bosnia and Herzegovina & B6, B7, B8 \\
Functionality of symbolical decorations & B9 \\
Stocking of products for immediate use & B10, B11, B12, B13 \\
Storytelling supported by Bosnian-Herzegovinian products & B14 \\
Purchase satisfaction dependant on the context of purchase & B15 \\
\hline
\end{tabular}

Source: Authors

\subsection{Discussion}

When returning back from Bosnia and Herzegovina, beside outbound presents diaspora members take with them an additional type of products. It is those products which diaspora members purchase in Bosnia and Herzegovina for personal usage when returning back to their new home reality. These products are one of the main components of the 'bridging' concept. Diaspora members appear to engage in bridging between the two realities of the country of origin and the country of current living; or, between reality of having a home country holiday to the reality of everyday life. Bridging is supposed to bumper the switch from one reality to another. Two bridging strategies have been detected: storytelling and product stocking.

Storytelling. Upon return to the country of current living, diaspora members gather with family and friends in order to share experiences of their visit to Bosnia and Herzegovina. Those experiences are presented by stories they tell about their visit. Stories are based on both, facts and interpretation. The fact-side of storytelling is more focused on presenting plain facts about the visit, such as, how long did one stay in the country of origin, which local places have been visited, whom the diaspora tourist has met, what products have been purchased, etc. The process of storytelling then moves to the more interpretative phase, as the storyteller starts to present the emic perspective of the mentioned places, people, products and brands. By telling stories about the visit, the storyteller exposes meanings attached to those facts, emotions which arose during the consumption process, symbolism that all the places, people, products, and brands are carrying. By exposing the emic perspective, the visit experience is presented in its full complexity.

Product stocking. This strategy implies two different types of products and is implemented through two major phases. In the first phase, stocked are products which symbolically represent the period when the diaspora member lived in the country of origin. The phase is labelled as 'symbolic representation filling phase' as it implies products which are symbolical representations of personal life, culture and the country. These products have usually a long durability and are carriers of strong symbolism 
ToSEE - Tourism in Southern and Eastern Europe, Vol. 6, pp. 81-94, 2021.

D. Berberović, E. Kurtović: STORYTELLING AND PRODUCT STOCKING

(personal photos, national items, souvenirs, etc.). Therefore, this phase can also be labelled as 'long-term stocking phase'.

In contrast to this, the second stocking phase, implies products of limited durability, usually not longer than when time comes for the next visit to Bosnia and Herzegovina. Those are usually items from product categories such as food, cosmetics, journals, etc. Hence the label 'short-term stocking phase'. Besides, these products usually comply with current consumer trends such as re-rooting, eco-friendly products, home-made products, etc.

Diaspora members, moved to the second phase after the initial, first phase, once they judged to have sufficiently filled their homes with symbolical representations of their past lives, past realities they were living in. Although products from the second phase are more attractive to diaspora consumers if they represent the country of origin. Even if such products can be purchased in specialized shops with international goods in the country of current living (Yin et al. 2017), diaspora members rather choose to purchase them during their visit. It is the context of purchasing in the country of origin which makes those products more symbolically-laden, and as such are perceived as more valuable.

A combination of the two bridging strategies - storytelling and product stocking - is also possible. Diaspora members invite friends and family over to consume short-term stocked products together while sharing travel experiences from the country of origin.

\section{CONCLUSION}

When diaspora members finish their travel to the country of origin, it has been observed that the symbolic bond between the diaspora tourist and the country of origin has been maintained and renewed (Capistrano and Weaver 2017). According to Griffin (2015), by travelling to the country of their origin diaspora tourists reconnect with their identities and authenticity of their origin. The empirical research presented in this paper does support these findings; but it also adds to it by suggesting that the travel does not finish once diaspora tourists are back to the country of their current living. Diaspora tourists have found ways of expanding their visit on a symbolical level upon return.

Diaspora tourists apply two strategies for expanding and reconstructing the travel experience, thereby creating a symbolic bridge between the reality they live in and the reality of their travel to the country of origin. The bridging is achieved by creating stocks of products they have brought from the travel. Diaspora members consume these symbolladen products slowly and partially in order to enjoy every bit of it but also to bridge the period until they visit again their country of origin.

Another bridging strategy is storytelling. By telling stories about their visit, diaspora tourists share experiences imbued with emotions, individual perceptions and other highly interpretative perspectives. And this is an important finding, as storytelling gains increasing relevance in tourism for several reasons. 
ToSEE - Tourism in Southern and Eastern Europe, Vol. 6, pp. 81-94, 2021.

D. Berberović, E. Kurtović: STORYTELLING AND PRODUCT STOCKING

The applicative nature of presented research findings appears to be relevant especially in terms of market positioning and promoting a destination. While souvenirs have long been recognized as an important carrier of destination brand values (Paraskevaidis and Andriotis 2015), storytelling's role in disseminating destination brand values have largely remained unrecognized within the community of tourism professionals. Storytelling provides a destination with a unique selling proposition, brand values and brand associations presented through the authentic testimonial of the tourist-teller (Woodside et al. 2007). Storytelling also influences other people to visits places (Martin and Woodside 2011) and it is one of the highly effective marketing strategies for revitalising brands, heritage, products and places, leading to enhancement of customer loyalty (Lee and Shin 2015). Furthermore, Chronis (2012) claims that so far promotion of destinations has been under tight scrutiny and control of destination marketing organizations (DMOs). But tourists' narratives about destinations have largely been ignored in promoting a specific destination, although they represent a powerful promotional tool as they are authentic and unique testimonials of a visited place (Woodside et al. 2007).

\section{REFERENCES}

Arnould, E.J. and Thompson, C.J. (2005), “Consumer Culture Theory (CCT): Twenty Years of Research", Journal of Consumer Research, Vol. 31, No. 4, pp. 868-882. https://doi.org/10.1086/426626

Belk, R.W. (1988), "Possessions and the Extended Self", The Journal of Consumer Research, Vol. 15, No. 2, pp. 139-168. https://doi.org/10.1086/209154

Bryce, D., Murdy, S. and Alexander, M. (2017), "Diaspora, Authenticity and the Imagined Past", Annals of Tourism Research, Vol. 66, pp. 49-60. https://doi.org/10.1016/j.annals.2017.05.010

Capistrano, R.C. and Weaver, A. (2017), "Host-guest interactions between first-generation immigrants and their visiting relatives: social exchange, relations of care and travel", International Journal of Culture, Tourism and Hospitality Research, Vol. 11, No. 3, pp. 406-420. https://doi.org/10.1108/IJCTHR-112016-0115

Ceisel, C.M. (2015), “Tourist Itineraries”, International Review of Qualitative Research, Vol. 8, No. 4, pp. 442-452. https://doi.org/10.1525/irqr.2015.8.4.442

Chronis, A. (2012), "Tourists as Story-Builders: Narrative Construction at a Heritage Museum", Journal of Travel \& Tourism Marketing, Vol. 29, No. 5, pp. 444-459. https://doi.org/10.1080/10548408.2012.691395

Corbin, J. and Strauss, A. (2015), Basics of Qualitative Research: Techniques and Procedures for Developing Grounded Theory, 4 th ed., Sage, Thousand Oaks.

Dutt, C. and Ninov, I. (2017), "Expatriates' learning: The role of VFR tourism”, Journal of Hospitality and Tourism Management, Vol. 31, pp. 253-264. https://doi.org/10.1016/j.jhtm.2017.03.003

Flick, U. (2009), An Introduction to Qualitative Research, 4 th ed., Sage, London.

Firat, A.F., Sherry, J.F. Jr and Venkatesh, A. (1994), "Postmodernism, marketing and the consumer", International Journal of Research in Marketing, Vol. 11, No. 4, pp. 311-317. https://doi.org/10.1016/01678116(94)90009-4

Griffin, T. (2015), "Considering the experience of hosting friends and relatives for immigrants", in Backer, E. and King, B. (Eds), Visiting Friends \& Relatives: Exploring the VFR Phenomenon, Channel View, Bristol, pp. 73-86.

Griffin, T. and Dimanche, F. (2017), "Urban tourism: the growing role of VFR and immigration", Journal of Tourism Futures, Vol. 3, No. 2, pp. 103-113. https://doi.org/10.1108/JTF-10-2016-0036

Holbrook, M.B. and Grayson, M.W. (1986), 'The Semiology of Cinematic Consumption: Symbolic Consumer Behavior in Out of Africa', Journal of Consumer Research, Vol. 13, pp. 374-381. https://doi.org/10.1086/209076

Huang, W.-J., Hung, K. and Chen C.-C. (2018), “Attachment to the home country or hometown? Examining diaspora tourism across migrant generations", Tourism Management, Vol. 68, pp. 52-65. https://doi.org/10.1016/j.tourman.2018.02.019 
ToSEE - Tourism in Southern and Eastern Europe, Vol. 6, pp. 81-94, 2021.

D. Berberović, E. Kurtović: STORYTELLING AND PRODUCT STOCKING

Hung, K., Xiao, H. and Yang, X. (2013), "Why immigrants travel to their home places: Social capital and acculturation perspective", Tourism Management, Vol. 36, pp. 304-313. http://dx.doi.org/10.1016/j.tourman.2012.12.010

Lee, Y.-S. and Shin, W.-J. (2015), "Marketing tradition-bound products through storytelling: a case study of a Japanese sake brewery", Service Business, Vol. 9, pp. 281-295 https://doi.org/10.1007/s11628013-0227-5

Li, T.E. and McKercher, B. (2016), "Developing a typology of diaspora tourists: Return travel by Chinese immigrants in North America", Tourism Management, Vol. 56, pp. 106-113. http://dx.doi.org/10.1016/j.tourman.2016.04.001

Lin, L. and Mao, P.-C. (2015), "Food for memories and culture - A content analysis study of food specialties and souvenirs", Journal of Hospitality and Tourism Management, Vol. 22, pp. 19-29. http://dx.doi.org/10.1016/j.jhtm.2014.12.001

Martin, D. and Woodside, A.G. (2011), "Storytelling research on international visitors: Interpreting own experiences in Tokyo", Qualitative Market Research: An International Journal, Vol. 14, No. 1, pp. 27-54. https://doi.org/10.1108/13522751111099319

MHRRBH - Ministry of Human Rights and Refugees in Bosnia and Herzegovina (2016), Diaspora and Development of Bosnia and Herzegovina, viewed 29 April 2021, https://bih.iom.int/sites/bih/files/downloads/publications/Diaspora\%20and\%20Development\%20o f\%20Bosnia\%20and\%20Herzegovina.pdf

Ourahmoune, N. (2016), "Narrativity, temporality, and consumer-identity transformation through tourism", Journal of Business Research, Vol. 69, pp. 255-263. http://dx.doi.org/10.1016/j.jbusres.2015.07.038

Paraskevaidis, P. and Andriotis, K. (2015), "Values of souvenirs as commodities", Tourism Management, Vol. 48, pp. 1-10. http://dx.doi.org/10.1016/j.tourman.2014.10.014 0261

Soukhathammavong, B. and Park E. (2019), "The authentic souvenir: What does it mean to souvenir suppliers in the heritage destination”, Tourism Management, Vol. 72, pp. 105-116. https://doi.org/10.1016/j.tourman.2018.11.015

Thompson, C.J. and Tambyah, S.K. (1999), "Trying to Be Cosmopolitan”. Journal of Consumer Research, Vol. 26, No. 3, pp. 214-241. https://doi.org/10.1086/209560

Tie, C., Holden, A. and Park, H.Y. (2015), “A 'reality of return': The case of the Sarawakian-Chinese visiting China”, Tourism Management, Vol. 47, pp. 206-212. http://dx.doi.org/10.1016/j.tourman.2014.09.021

UKMFA - United Kingdom Ministry of Foreign Affair (2020), Entering the European market for diaspora tourism, viewed 29 April 2021, https://www.cbi.eu/market-information/tourism/diasporatourism/market-entry

UNWTO - United Nations World Travel Oranization (2017), UNWTO Annual Report 2016, viewed 29 April 2021, https://www.e-unwto.org/doi/book/10.18111/9789284418725

Venkatesh, A., Sherry, J.F. Jr and Firat, A.F. (1993), „Postmodernism and the marketing imaginary“, International Journal of Research in Marketing, Vol. 10, No. 3, pp. 215-224. doi: 10.1016/01678116(93)90007-L

Weaver, D.B., Kwek, A. and Wang, Y. (2017), "Cultural connectedness and visitor segmentation in diaspora Chinese tourism”, Tourism Management, Vol. 63, pp. 302-314. http://dx.doi.org/10.1016/j.tourman.2017.06.028

Wilson, K. and Desha, C. (2016), "Engaging in design activism and communicating cultural significance through contemporary heritage storytelling", Journal of Cultural Heritage Management and Sustainable Development, Vol. 6, No. 3, pp. 271-286. https://doi.org/10.1108/JCHMSD-10-20150039

Witt, U. (2010), "Symbolic consumption and the social construction of product characteristics", Structural Change and Economic Dynamics, Vol. 21, No. 1, pp. 17-25. https://doi.org/10.1016/j.strueco.2009.11.008

Woodside, A.G., Cruickshank, B.F. and Dehuang, N. (2007), "Stories visitors tell about Italian cities as destination icons", Tourism Management, Vol. 28, pp. 162-174. https://doi.org/10.1016/j.tourman.2005.10.026

Yin, C.-Y., Poon, P. and Su, J.-L. (2017), "Yesterday once more? Autobiographical memory evocation effects on tourists' post-travel purchase intentions toward destination products", Tourism Management, Vol. 61, pp. 263-274. http://dx.doi.org/10.1016/j.tourman.2017.02.014

Zaltman, G. (2003), How consumers think, Harvard Business School Press, Boston. 
ToSEE - Tourism in Southern and Eastern Europe, Vol. 6, pp. 81-94, 2021.

D. Berberović, E. Kurtović: STORYTELLING AND PRODUCT STOCKING .

Denis Berberović, $\mathrm{PhD}$, Assistant Professor School of Economics and Business Sarajevo Marketing Department

Trg oslobođenja-Alija Izetbegović 1

Sarajevo, Bosnia and Herzegovina

+38761253551

denis.berberovic@efsa.unsa.ba

Emir Kurtović, PhD, Full Professor

School of Economics and Business Sarajevo

Marketing Department

Trg oslobođenja-Alija Izetbegović 1

Sarajevo, Bosnia and Herzegovina

+38733275937

emir.kurtovic@efsa.unsa.ba 